Characterization of a Nitrogenbased Dielectric Barrier Discharge Ionization Source for Mass Spectrometry Reveals Factors Important for Soft Ionization

\author{
Journal Article \\ Author(s): \\ Gyr, Luzia; Klute, Felix D.; Franzke, Joachim; Zenobi, Renato (D) \\ Publication date: \\ 2019 \\ Permanent link: \\ https://doi.org/10.3929/ethz-b-000340425
}

Rights / license:

In Copyright - Non-Commercial Use Permitted

Originally published in:

Analytical Chemistry 91(10), https://doi.org/10.1021/acs.analchem.9b01132 


\title{
Characterization of a Nitrogen-Based Dielectric Barrier Discharge lonization Source for Mass Spectrometry Reveals Factors Important for Soft lonization
}

\author{
Luzia Gyr, Felix D. Klute ${ }^{\dagger}$, Joachim Franzke ${ }^{\dagger}$ and Renato Zenobi* \\ Department of Chemistry and Applied Bioscience, ETH Zurich, CH-8093 Zurich, Switzerland \\ $\uparrow$ Leibniz-Institut für Analytische Wissenschaften - ISAS - e.V., Bunsen-Kirchhoff-Straße 11, 44139 \\ Dortmund, Germany \\ * Corresponding Author E-mail: zenobi@org.chem.ethz.ch
}

\begin{abstract}
Atmospheric pressure plasma-based ionization coupled to mass spectrometry is a powerful analytical technique. However, the characteristics of existing ionization sources, especially regarding the reactive species and the effect of the discharge type on the soft ionization, are often not well described. In this work, the active capillary plasma ionization source, which is based on a dielectric barrier discharge, was characterized by optical emission spectroscopy and mass spectrometry. To obtain a better understanding of the requirements for a soft ionization, several reactive species and the energy of the ionization reaction were identified. Charged reactive species such as $\mathrm{H}_{3} \mathrm{O}^{+}, \mathrm{N}_{2}{ }^{\bullet}, \mathrm{N}_{2} \mathrm{H}^{+}, \mathrm{NO}^{+}, \mathrm{N}_{3}^{+}$ and $\mathrm{N}_{4}{ }^{+\bullet}$ as well as uncharged species (most probably the excited neutral nitrogen) were all found to contribute to the soft ionization process in dielectric barrier discharge. The energy in the plasma was determined to be in the range from 8-16 eV, based on the ionization energy of nitrogen and the measurements of tungsten hexacarbonyl. Furthermore, not only the type of reactive species was relevant for achieving a soft ionization, it was also crucial that the sample was injected through the inner electrode, which leads to nearly no direct contact with the discharge filaments.
\end{abstract}

Plasma-based ambient desorption ionization mass spectrometry is a fast, simple and direct analysis of various types of samples. ${ }^{1}$ Applications have been developed for many different fields such as bioanalytics, environmental sciences and pharmaceutical sciences. ${ }^{2,3}$ Since the introduction of ambient ionization by Cooks et al. in $2004^{4}$, more than 70 different ambient ionization techniques have been reported..$^{5}$ A category of it are plasma-based ionization sources, which are able to ionize polar and nonpolar compounds with almost no fragmentation. The various plasma-based ionization sources differ mainly in the type of discharge, the type of excitation and the configuration of the electrodes. ${ }^{1}$ The type of discharge (e.g. homogenous or filamentary discharge) depends on the plasma parameters and on the setup of the plasma source. How the type of the discharge determines whether soft ionization is possible has not been systematically studied. Moreover, the ionization process in the plasma is complex and often not completely known due to the many different constituents of a plasma, such as positive and negative ions, electrons, excited states, atoms, free radicals and photons. ${ }^{6}$ Despite the large number of reactive species present in a plasma, most of these low-temperature plasma ionization techniques produce molecular ions (e.g. $\mathrm{MH}^{+}, \mathrm{M}^{+\bullet}, \mathrm{M}_{-} \mathrm{H}^{-}, \mathrm{M}^{\bullet}$ ) with nearly no fragment ions. The aim of the present study is to reveal the factors responsible for the soft ionization in a plasma-based ionization source for molecular mass spectrometry. This is not only essential for gaining insight into the ionization process but is also for the optimization of the performance of the source in real-world applications. A crucial step toward a better understanding of the soft ionization process is the identification of the reactive species. $\mathrm{N}_{2}{ }^{\bullet}$ ions are generally considered as the key reagent ions for soft plasma-ionization in mass spectrometry due to their capability of direct and indirect ionization of the analyte. ${ }^{7}$ 
The formation of the $\mathrm{N}_{2}{ }^{+\bullet}$ ions depends strongly on the discharge gas. In a helium plasma, the $\mathrm{N}_{2}{ }^{+\bullet}$ ions are formed mostly by Penning ionization of metastable helium ${ }^{8}$ and in the nitrogen plasma by stepwise electron impact ionization ${ }^{9}$. $\mathrm{N}_{3}{ }^{+}$and $\mathrm{N}_{4}{ }^{+}$ions have only been reported in atmospheric pressure chemical ionization (APCI) so far. ${ }^{10}$ Nevertheless, for various other plasma ionization sources $\mathrm{N}_{4}{ }^{\bullet}$ ions have been proposed as key intermediates for the formation of water clusters, which are a source of protons for analytes with high proton affinity. ${ }^{7}$ Water clusters can also be formed by metastable helium ${ }^{11}$ and are the dominating species in background mass spectra obtained in positive mode using direct analysis in real time $(\mathrm{DART})^{12}$, flowing atmospheric -pressure afterglow (FAPA) $)^{13}$ or the low temperature plasma probe (LTP) $)^{14}$. Additionally, background ions such as $\mathrm{O}_{2}^{+\bullet}$ and $\mathrm{NO}^{+}$ions have been observed in these ionization sources and are involved in charge transfer and/or hydride abstraction reactions. ${ }^{3}$ Low-energy electrons, which are known to occur in the plasma, react with the analyte by electron impact ionization or electron capture. ${ }^{1}$

This work focuses on dielectric barrier discharge ionization (DBDI) in a controlled atmosphere, which produces a stable plasma at atmospheric pressure when using nitrogen, air or helium as discharge gas. It was first introduced in combination with mass spectrometry by $\mathrm{Na}$ et al. in 2007 by detection of amino acids. ${ }^{15}$ In the nitrogen DBD, various species including ammonia cluster, $\mathrm{NO}^{+}$and $\mathrm{N}_{2}{ }^{+}$have been identified. ${ }^{16,17}$ However, in all of these studies the nitrogen DBD sources were operated in an open atmosphere, which allowed little control over the composition of the gases in the atmosphere. The reactive species might therefore be different in a controlled atmosphere.

Optical emission spectroscopy (OES) has proven to be particularly suitable for the characterization of low temperature plasma sources. ${ }^{18}$ Since most DBD ionization sources are operated with helium or argon, nitrogen-based DBD sources have not been extensively studied with OES yet. ${ }^{5}$ However, nitrogen-based DBD sources are getting more attention, not only due to the lower operating cost compared with noble gas, but also due to the capability of coupling the ionization source directly to the MS inlet, providing complete transportation of the ions.

Our lab has previously designed an active capillary plasma ionization source (based on DBD) that can be operated with nitrogen and other discharge gases. ${ }^{19}$ The capability of this source for soft ionization has been shown in recent publications $^{20-22}$ and a radical-mediated pathway in positive mode has been discovered ${ }^{23}$. However, to date, little is known about the process of soft ionization in nitrogen DBD. The active capillary plasma ionization source is particularly suited for mechanistic studies since the gas-phase conditions can be precisely controlled. Here, we made use of this feature and characterized the active capillary plasma ionization source under different plasma conditions to identify the type of discharge and study the influence on soft ionization. Plasma constituents such as positive ions, electrons and uncharged molecules were determined in order to identify the reactive species responsible for the soft ionization process.

\section{EXPERIMENTAL SECTION}

\section{Chemicals}

Benzene (99.7 \%) was purchased from Sigma-Aldrich Chemie GmBH (Buchs, Switzerland). Butyl 2-aminobenzoate was obtained from Tokyo Chemical Industry (Eschborn, Germany). Tungsten hexacarbonyl (99\%) was purchased from abcr GmbH (Karlsruhe, Germany).

\section{Sample Introduction System}

Liquid samples were vaporized as described in recent publications. ${ }^{20,24}$ In brief, a pressurized sample vial (0.9 bar overpressure), was connected via a fused silica-capillary (40 $\mu \mathrm{m} \mathrm{ID,} 30 \mathrm{~cm}$ length) to a hollow heat cartridge $\left(200{ }^{\circ} \mathrm{C}\right.$, $1.3 \mathrm{~L} / \mathrm{min}$ nitrogen). Headspace analysis was performed for the measurements of tungsten hexacarbonyl. The compound was placed in a chamber that was directly connected to the active capillary plasma ionization source. The chamber was 
flushed with nitrogen at a flow rate of $1 \mathrm{~L} / \mathrm{min}$. Samples were introduced with a gas flow through the inner electrode of the plasma source.

\section{Active Capillary Plasma Ionization Source}

An active capillary plasma ionization source, described previously ${ }^{19,24}$, was used in this work. Briefly, the source contains an inner electrode (ground, stainless steel, ID: $0.6 \mathrm{~mm}$ and OD: $1.0 \mathrm{~mm}$ ) and an outer electrode (copper, ID: $1.55 \mathrm{~mm}$, surrounding the glass capillary) to which a sine- or square wave-modulated high voltage $\left(2-4 \mathrm{kV} \mathrm{pp}_{1}, 5-47 \mathrm{kHz}\right)$ is applied, separated by a glass capillary. The inner electrode and outer electrode overlapped by $1.8 \mathrm{~mm}$. A schematic of the plasma source is shown in Figure 1a. It is worth mentioning that the voltage was varied up to around $3.0 \mathrm{kV}_{\mathrm{pp}}$ and the frequency between $5-47 \mathrm{kHz}$ in the different experiments reported in this study. However, this did not affect the capability of soft ionization, but rather the ionization efficiency. Nitrogen (purity N4.5), oxygen (N4.5), carbon dioxide (N4.5) or helium (N5.0) was used as carrier and discharge gases. The plasma source was directly connected to the mass spectrometer through a modified ion transfer capillary. The pressure in the plasma source was nearly at atmospheric pressure; a pressure difference of only $67 \mathrm{mbar}$ to atmosphere was measured. A slightly modified active capillary plasma ionization source (Figure 1b) was used to introduce the sample between the inner electrode and the glass capillary providing a direct contact of the analyte with the discharge. The geometry of the plasma source as well as the total gas flow did not change from the first version (Figure 1a).

In order to confirm that uncharged species could also ionize the analyte, a third design was used (Figure 1c), in which three different electrodes were placed between the active capillary plasma ionization source and the MS ion transfer capillary. The first electrode was grounded and to the second and the third electrodes, $300 \mathrm{~V}$ and $30 \mathrm{~V}$ were applied, respectively to eliminate any ions and electrons before sample introduction. The sample was introduced with a flow rate of $0.1 \mathrm{~L} / \mathrm{min}$ after the third electrode. The nitrogen flow rate through the inner electrode of the plasma source was set to $0.75 \mathrm{~L} / \mathrm{min}$.

\section{Mass Spectrometry}

Mass spectra were acquired in positive ion mode, either with a LTQ ion trap MS or with a LTQ Orbitrap MS (both from Thermo Fischer Scientific, San Jose, U.S.A.) and using 3 microscans and a maximum injection time of $100 \mathrm{~ms}$. The mass-to-charge range was set to 15-200 for the LTQ ion trap MS or m/z 50-500 for the LTQ Orbitrap MS.

\section{Optical Emission Spectroscopy}

For optical emission spectroscopy measurements, two different UV-VIS spectrometers (Ocean Optics USB 2000, Largo FL, U.S.A and Echelle Spectra Analyzer ESA 3000 EV, LLA Instruments GmbH, Berlin-Adlershof, Germany) were used. An optical fiber was used to measure the emission in the range of 200-850 nm. In order to be able to observe short, transient discharge filaments, an intensified CCD camera (iCCD; Andor DH 720 18F-03, Belfast, UK) was used, which had a spectral range from $180-850 \mathrm{~nm}$. All measurements were carried out along the axis of the active capillary plasma ionization source. 
a)

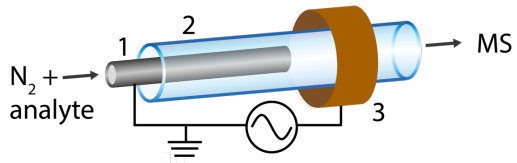

b)
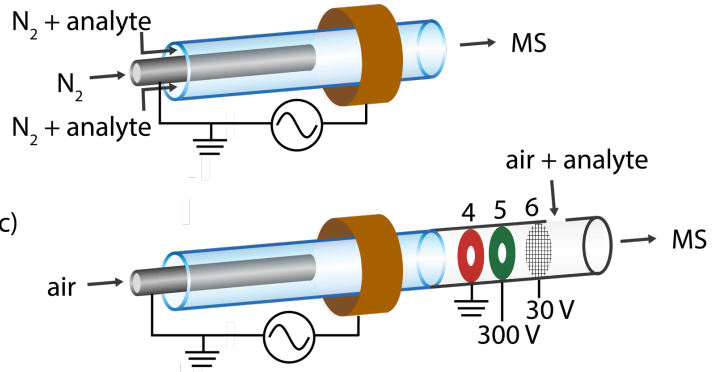

Figure 1: a) Schematic drawing of the active capillary plasma ionization source, which contains an inner electrode (1), a glass capillary (2) and an outer electrode (3). b) Schematic drawing of the modified active capillary plasma ionization source for introducing the sample between the inner electrode (1) and the glass capillary (2). c) Schematic drawing of the active capillary plasma ionization source coupled to the perforated disk electrodes $(4,5)$ and grid electrode $(6)$. The first electrode (4) was grounded and $300 \mathrm{~V}$ and $30 \mathrm{~V}$ were applied to the second (5) and third electrode (6), respectively.

\section{RESULTS and DISCUSSION}

\section{Filamentary Discharges Lead to Soft Ionization}

The active capillary plasma ionization source was first characterized by defining the location and type of discharge. Additionally, the influence of the applied waveform (sine or square wave) on the soft ionization was investigated, as a square waves was found to produce higher current spikes at the rising edges compared to a sine wave. iCCD images taken on-axis of the nitrogen plasma source revealed that the plasma forms between the inner electrode and the glass capillary when applying a sine- or square wave-modulated high voltage to the outer electrode, as shown in Figure 2a and b. For both waveforms, microdischarges were observed. These filaments were not only visible in the iCCD images, but also in the short current spikes (ns) shown in an earlier study for a sine wave ${ }^{24}$, which is typical for filamentary discharges. ${ }^{25}$ The square wave $\left(3.0 \mathrm{kV}_{\mathrm{pp}}\right)$ was found to produce more intense filaments than the sine wave $\left(3.5 \mathrm{kV} \mathrm{pp}_{\mathrm{pp}}\right.$ ), which can also be seen in the optical emission measurements along the axis of the plasma source (Figure S1). Nevertheless, in both cases a soft ionization of organic molecules was possible by introducing the sample through the inner electrode, as shown for butyl 2-aminobenzoate (Figure $2 \mathrm{c}$ and $\mathrm{d}$ ). In order to determine the influence of the filamentary discharges on analyte ionization, the setup was modified to allow injection of the analyte between the inner electrode and glass capillary (see schematic of the setup in Figure 1b). Using this setup, the analyte was forced to come into contact with the filamentary discharges, leading to the observation of fragmentation and clustering (Figure 2e and f), which does not occur in the other setup. In order to provide a direct contact of the sample with the plasma filaments, a nitrogen flow rate of $0.8 \mathrm{~L} / \mathrm{min}$ between the inner electrode and the glass capillary and of $0.2 \mathrm{~L} / \mathrm{min}$ through the inner electrode was used. The same flow rates were also applied when introducing the analyte through the inner electrode (Figure S2) to rule out that the fragmentation was caused by the different flow rates. Only a very minor influence of the nitrogen flow rate on the ionization behavior was observed. The increased fragmentation observed when using a square wave and a direct contact with the filaments for ionization indicates a waveform-based effect. This could be explained by the higher current spikes that are created with the square wave, leading to a higher charge density than using a sine wave. However, the waveforms had nearly no effect on the softness of the ionization when the analyte had no contact 
with the discharge filaments. In general, these results demonstrate that not only the identification of reactive species is important but also the way how the analyte is introduced to the discharge filaments.

a)

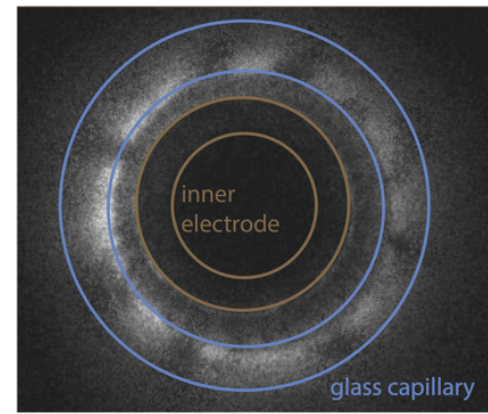

b)

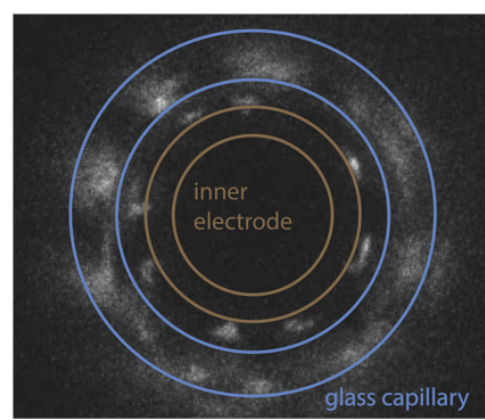

c)

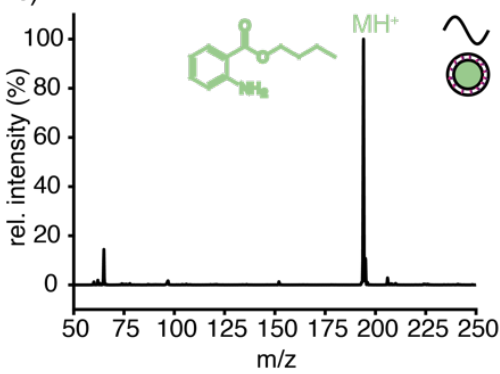

d)

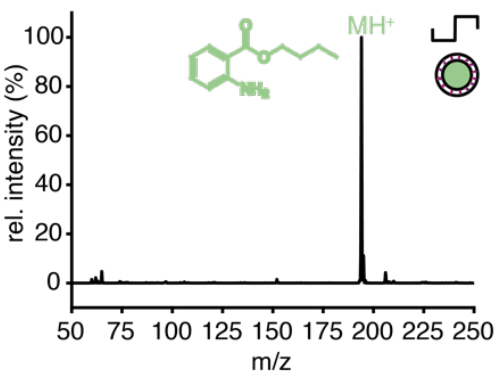

e)

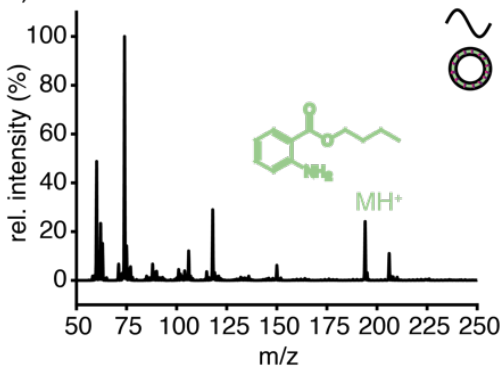

f)

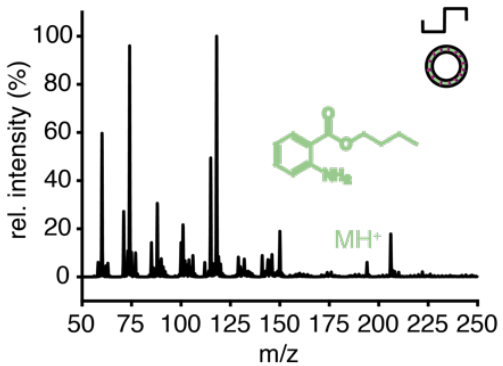

Figure 2: An image of the cross section of the nitrogen active capillary plasma ionization source recorded with an iCCD camera using a) sine $\left(3.5 \mathrm{kV}_{\mathrm{pp}}, 5 \mathrm{kHz}\right.$, average time of $\left.199 \mu \mathrm{sec}\right)$ or b) square wave $\left(3.0 \mathrm{kV}_{\mathrm{pp}}, 20 \mathrm{kHz}\right.$, average time of $24 \mu \mathrm{sec}$ ). The mass spectrum of butyl 2-aminobenzoate in methanol was obtained when the sample was introduced through the inner electrode by applying c) sine wave and d) square wave. A nitrogen flow rate of $1 \mathrm{~L} / \mathrm{min}$ through the inner electrode was used. If the sample was introduced through the filamentary discharges (between the inner electrode and glass capillary), fragmentation and clustering were obtained with e) sine wave and as well with $\mathrm{f}$ ) square wave. A nitrogen flow rate of $0.8 \mathrm{~L} / \mathrm{min}$ between the inner electrode and the glass capillary and of $0.2 \mathrm{~L} / \mathrm{min}$ through the inner electrode was used.

\section{Energy of Reactive Species}

In order to estimate the available energy for the ionization process, tungsten hexacarbonyl $\left(\mathrm{W}(\mathrm{CO})_{6}\right)$ was measured. Energies required for ionization and fragmentation are well known from electron ionization data and can be used to provide an estimate for the electron energies in DBDI. ${ }^{26}$ Additionally, W(CO) ${ }_{6}$ has already been used in microsecond pulsed glow discharge $(8.6-21.0 \mathrm{eV})^{27}$, which allows a comparison of the two techniques. However, appearance energies have to be taken with care, since in both cited references, the ionization process did not occur at atmospheric pressure as in the case of the active capillary plasma ionization source. When measuring the tungsten hexacarbonyl sample, the dominant peak was $\mathrm{W}(\mathrm{CO})_{6}{ }^{+}$, which requires an ionization energy of $8.5 \mathrm{eV}$ (Figure 3). Additionally, $\mathrm{W}(\mathrm{CO})_{5}{ }^{+}$was observed, which has an ionization energy of about $10 \mathrm{eV}$. In contrast to the other ionization techniques, also other reaction products were obtained such as $\mathrm{W}(\mathrm{CO})_{4}(\mathrm{OH})^{+}$and $\mathrm{W}(\mathrm{CO})_{3}(\mathrm{OH})^{+}$, showing that not only electrons react with tungsten hexacarbonyl. No fragments with less than two CO ligands were obtained, therefore the energy for these 
reaction provided by the plasma is likely lower than $16.3 \mathrm{eV} \cdot{ }^{26}$ Using the data on $\mathrm{W}(\mathrm{CO})_{6}$ and further considering the ionization energy for nitrogen $\left(15.7 \mathrm{eV}^{28}\right)$, the energy range of the reactive species generated in the active capillary plasma ionization source can be estimated to lie in the range of 8-16 eV.

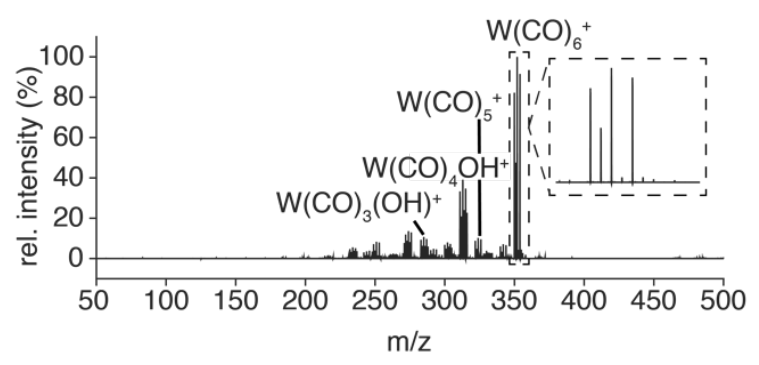

Figure 3: High-resolution mass spectrum of $\mathrm{W}(\mathrm{CO})_{6}$ introduced using head space analysis and ionized using sine wave $(2.8$ $\mathrm{kV}_{\mathrm{pp}}, 47 \mathrm{kHz}$ ). Nitrogen was used as carrier and discharge gas.

\section{Optical Emission Spectroscopy}

In order to identify the reactive species of the filamentary discharges, optical emission spectroscopy measurements were performed on-axis of the active capillary plasma ionization source operation in an open atmosphere. The lines in the emission spectrum obtained in the nitrogen DBD (Figure 4) were assigned to molecular nitrogen $\mathrm{N}_{2}\left(\mathrm{C}^{3} \Pi_{\mathrm{u}}-B^{3} \Pi_{g}^{-}\right.$ transitions, the second positive system) and $\mathrm{N}_{2}{ }^{\bullet}\left(\mathrm{B}^{2} \Sigma_{\mathrm{u}}^{+}-X^{2} \Sigma_{g}^{+} \text {transitions, first negative system }\right)^{29}$ and nitrogen monoxide NO $\left(A^{2} \Sigma^{+}-X^{2} \Pi_{r} \text { transitions, } \gamma \text {-system }\right)^{30}$. The emission line of $N_{2}(0,0)$ is cut off, due to the saturation of the detector. The ratio of $\mathrm{N}_{2}(0,0)$ to $\mathrm{N}_{2}(0,1)$ is 1.5 , which can be seen for example in Figure $\mathrm{S} 1$. The intensity of the $\mathrm{N}_{2}{ }^{+}$ emission lines is low compared to that of the $\mathrm{N}_{2}$ emission lines but they were still detectable. However, the intensity of the $\mathrm{N}_{2}{ }^{+}$transitions (e.g. $391.5 \mathrm{~nm}$ ) was significantly lower when using nitrogen as discharge gas compared to using helium, as shown in Figure S3. This difference in the emission intensity of $\mathrm{N}_{2}^{+\bullet}$ can originate from different underlying ionization pathways. In a helium DBD, the excited state of $\mathrm{N}_{2}{ }^{\bullet}$ (nitrogen is originating mostly from the atmosphere) is primarily populated via Penning ionization by metastable helium ${ }^{31}$. In the nitrogen plasma, however, the $\mathrm{N}_{2}^{+\bullet}$ state is mostly populated by stepwise electron impact ionization. ${ }^{9}$ The intensity of the emission line at $391.5 \mathrm{~nm}\left(\mathrm{~N}_{2}{ }^{+\bullet}\right.$ transition $)$ increased with increasing plasma voltage in the nitrogen DBD (Figure S4), due to the increased number and energy of the electrons. However, the emission of $\mathrm{N}_{2}{ }^{\bullet}$ transition was still lower than in a helium DBD, therefore the question arises if the ground state of $\mathrm{N}_{2}{ }^{\bullet}$ in a nitrogen DBD is also less occupied than in a helium DBD or $\mathrm{N}_{2}^{+\bullet}$ might not be the key intermediate for soft ionization in nitrogen DBD. Consequently, other essential reactive species (charged or uncharged) might exist and be essential for the ionization. This possibility will be further investigated in the next section.

Since protonated water $\left(\mathrm{H}_{3} \mathrm{O}^{+}\right)$can be a reactive species for protonation of the analyte ${ }^{7}$, the effect of water on the emission spectrum was studied by humidifying the nitrogen gas $\left(100 \%\right.$ rel. humidity at $\left.25{ }^{\circ} \mathrm{C}\right)$. The emission lines of nitrogen oxide $\left(\mathrm{A}^{2} \Sigma^{+}-\mathrm{X}^{2} \Pi_{\mathrm{r}}\right)$ and molecular nitrogen $\left(\mathrm{C}^{3} \Pi_{\mathrm{u}}-B^{3} \Pi_{g}^{-}\right)$were decreased in humidified nitrogen compared to pure nitrogen gas (Figure S5). The decreased emission can be explained by the competing electron impact ionization of water, which quenches the excitation of nitrogen and nitrogen oxide. Air and $\mathrm{CO}_{2}$ can also be used as discharge gas for the active capillary plasma ionization source coupled to the mass spectrometer. In the air or carbon dioxide DBD, the emission lines of NO were almost absent and the intensity of emission lines of $\mathrm{N}_{2}$ were decreased compared to pure nitrogen as discharge gas (Figure S6). This is most probably due to the lower amounts of nitrogen in 
air and $\mathrm{CO}_{2}$ compared to pure nitrogen gas and due to quenching effects. Additionally, electrons might react with other species in air and $\mathrm{CO}_{2}$, which have no optical emission but might be ionized.
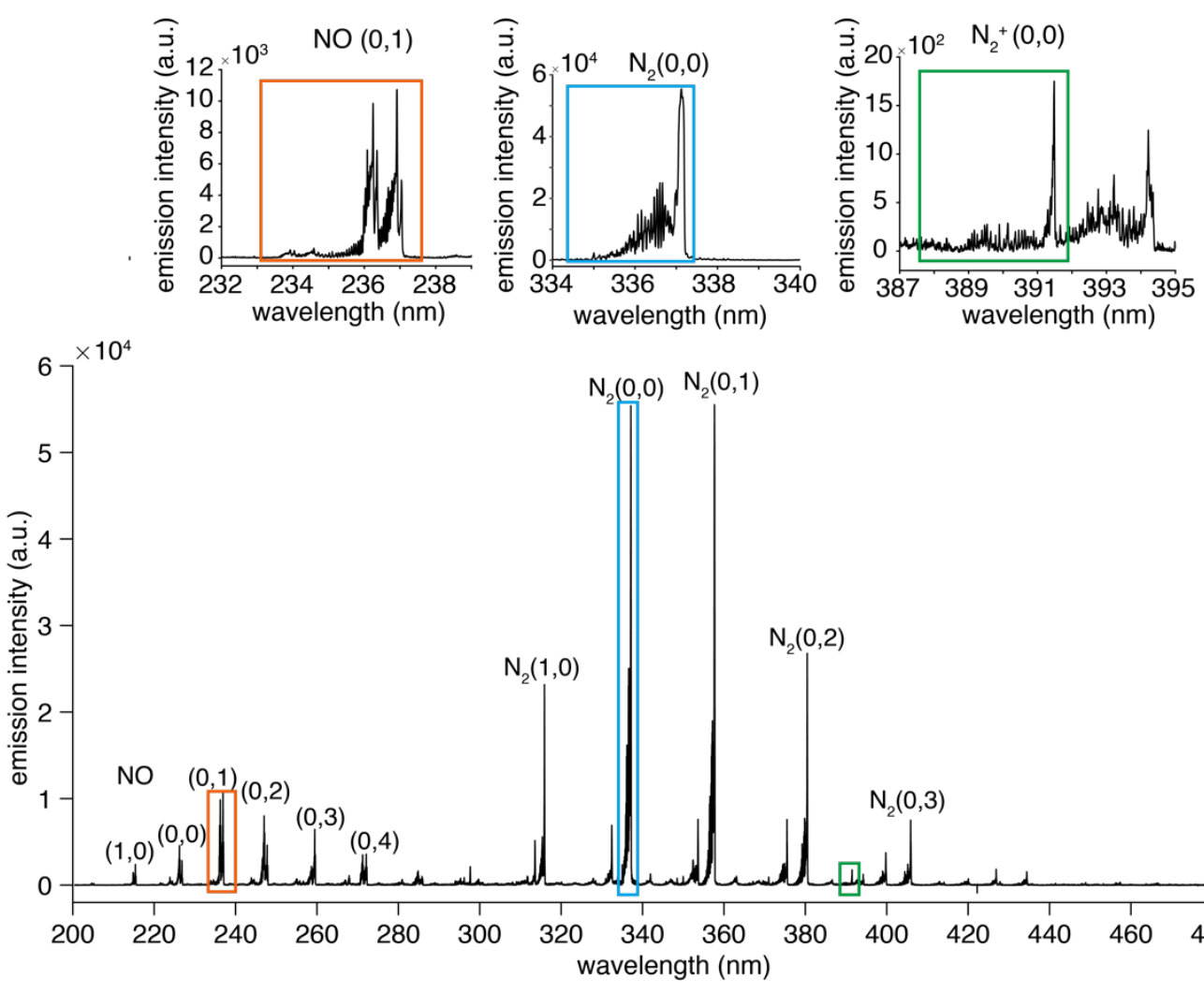

Figure 4: Bottom: Optical emission spectrum observed along the axis of the active capillary plasma ionization source operated in nitrogen $(4 \mathrm{kVpp}$ and $11 \mathrm{kHz})$. The emission line of $\mathrm{N}_{2}(0,0)$ is cut off, due to the saturation of the detector. The ratio of $\mathrm{N}_{2}(0,0)$ to $\mathrm{N}_{2}(0,1)$ is normally 1.5 . Top: A zoom-in to three different transitions: the second positive system $\left(\mathrm{N}_{2}\left(C^{3} \Pi_{\mathrm{u}}-\right.\right.$ $\left.B^{3} \Pi_{g}^{-}\right)$transitions $)$, first negative system $\left(\mathrm{N}_{2}^{+} \bullet\left(\mathrm{B}^{2} \Sigma_{\mathrm{u}}^{-}-X^{2} \Sigma_{g}^{+}\right)\right.$transitions $)$and $\gamma$-system $\left(\mathrm{NO},\left(\mathrm{A}^{2} \Sigma^{+}-\mathrm{X}^{2} \Pi_{\mathrm{r}}\right)\right.$ transitions $)$.

\section{Charged Reactive Species}

In order to investigate the different reactive charged species by using different discharge gases (air, $\mathrm{CO}_{2}$, humidified $\mathrm{N}_{2}$ or pure $\mathrm{N}_{2}$ ), the active capillary plasma ionization source was coupled to the mass spectrometer. The following charged species were obtained in a nitrogen DBD: $\mathrm{H}_{3} \mathrm{O}^{+}, \mathrm{N}_{2}^{+}, \mathrm{N}_{2} \mathrm{H}^{+}, \mathrm{NO}^{+}, \mathrm{N}_{3}^{+}$and $\mathrm{N}_{4}^{+}$(Figure 5). All of these species exhibit soft ionization characteristics. $\mathrm{H}_{3} \mathrm{O}^{+}$and $\mathrm{NO}^{+}$react with hydrocarbons and nitrogen compounds through proton transfer and charge transfer reactions (fragmentation possible), respectively, as shown by Španěl and Smith ${ }^{32,33}$ using selected ion flow tube mass spectrometry. Additionally, Milligan et al. ${ }^{34}$ reported that $\mathrm{N}_{2} \mathrm{H}^{+}$is capable of acting as a protonating agent, but can induce dissociation. $\mathrm{N}_{4}{ }^{+\bullet}$ ions have also been observed in nitrogen corona discharges and were proposed as the reagent ions for generating protonated water clusters. ${ }^{10}$ In the nitrogen DBD, no protonated water cluster were obtained, since nitrogen gas (purity $\mathrm{N} 4.5,<10 \mathrm{ppm}_{2} \mathrm{O}$ ) was used. Water clusters or ammonia water clusters were reported as the dominating species in the mass spectrum when using DART ${ }^{12}$ or nitrogen and helium $\mathrm{DBD}^{16}$, respectively. These clusters might form mostly due to air moisture, since both sources are operated in the open 
atmosphere. Our plasma source operates in a closed system and therefore the gas-phase conditions can be precisely chosen.

If we used pressurized air, the $\mathrm{O}_{2}^{+\bullet}$ ion was the most abundant peak and no nitrogen ions were obtained. This is due to the lower ionization energy of $\mathrm{O}_{2}^{+\bullet}\left(\mathrm{IE}=12.6 \mathrm{eV}^{35}\right)$ compared to $\mathrm{N}_{2}^{+\bullet}\left(\mathrm{IE}=15.7 \mathrm{eV}^{36}\right) . \quad \mathrm{O}_{2}^{+\bullet}$ is known to be predominantly a reagent ion for charge transfer with nitrogen compounds and hydrocarbons. ${ }^{32,33}$ In the $\mathrm{CO}_{2}$ plasma, $\mathrm{NO}^{+}$, $\mathrm{CO}_{2}^{+\bullet}, \mathrm{CO}_{2} \mathrm{H}^{+}$and $\left(\mathrm{CO}_{2}\right)_{2} \mathrm{H}^{+}$were observed. Under this plasma condition, tertiary amines can be oxidized, as shown in our previous study. ${ }^{23}$ In the humidified nitrogen DBD, the protonated water cluster $\left(\mathrm{H}_{2} \mathrm{O}\right) \mathrm{H}_{3} \mathrm{O}^{+}$was the dominant signal, which is a proton transfer reactant. This is in agreement with the OES measurements described above. The emission intensity of $\mathrm{N}_{2}$ and $\mathrm{NO}$ decreased in humidified nitrogen compared to pure nitrogen. Therefore, water might suppress the electron impact ionization of nitrogen or the charged nitrogen species might react with water resulting in only water cluster ions. Additionally, it has been shown that humidified nitrogen promotes protonation of the analyte and suppresses fragmentations compared to pure $\mathrm{N}_{2}{ }^{23,37}$

The capability to choose different discharge gases allows the generation of different reactive species, which all showed soft ionization characteristics. Proton transfer could be promoted by using humidified nitrogen, oxidation reactions could be facilitated by using carbon dioxide, and charge transfer reactions could be enhanced by using pure nitrogen or air as discharge gas.

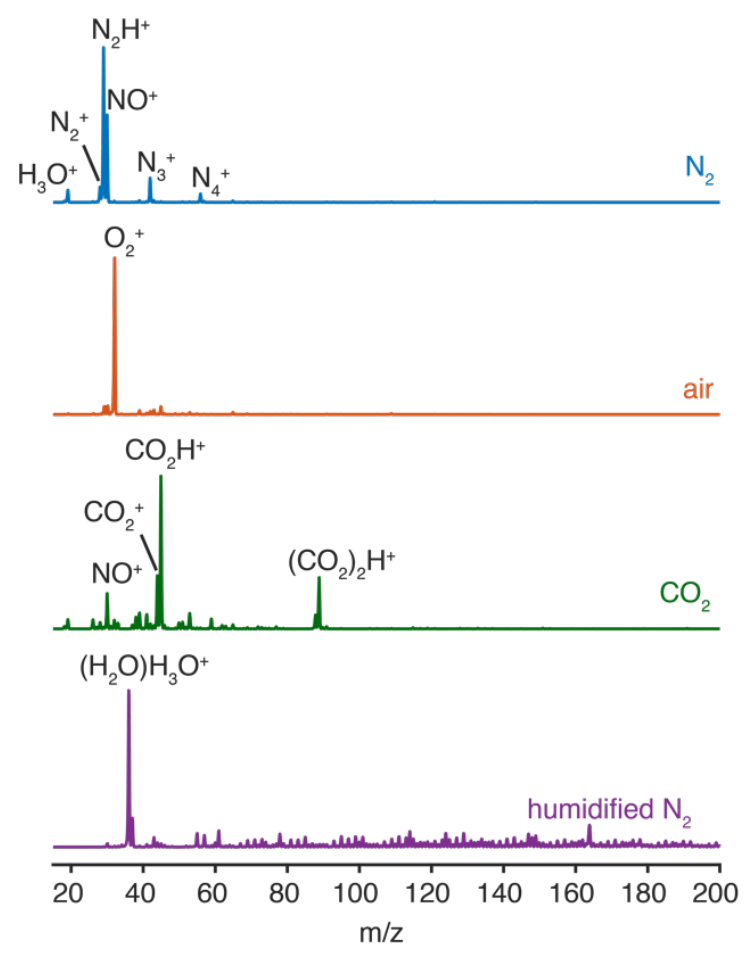

Figure 5: Mass spectra of the low mass ions, using nitrogen, air, $\mathrm{CO}_{2}$ or humidified nitrogen as discharge gas $(3.0 \mathrm{kV}$ pp 47 $\mathrm{kHz}$ ), which were measured with the IT MS using settings optimized for low mass.

\section{Uncharged Reactive Species}

Another reactive species might be excited neutral nitrogen, which showed the most intense emission lines $\left(\mathrm{N}_{2}\left(\mathrm{C}^{3} \Pi_{\mathrm{u}}-\right.\right.$ $B^{3} \Pi_{g}^{-}$) in the optical emission spectra (Figure 4). Excited neutral nitrogen might ionize the analyte by Penning 
ionization, as already suggested previously ${ }^{16}$. In order to confirm this hypothesis, all charged species, including ions and electrons generated by the plasma were removed before the sample was introduced into the setup. This was achieved by placing two perforated disk electrodes and a grid electrode between the plasma source and the MS ion transfer capillary (schematic of the setup in Figure 1c). Benzene was chosen as model compound, since its ionization potential $\left(9.7 \mathrm{eV}^{38}\right)$ is similar to but slightly lower than that of excited nitrogen $\left(11.1 \mathrm{eV}^{28}\right)$. Air was chosen as the discharge gas, since the emission lines of excited neutral nitrogen were found to be dominating in the OES measurement of the air-operated DBD (Figure S6). The mass spectrum of pure air recorded with inactive disk/grid electrodes has a dominant peak of $\mathrm{O}_{2}{ }^{+\bullet}$ (Figure 6a). $\mathrm{MH}^{+}$and $\mathrm{M}^{+\bullet}$ ions were obtained during the injection of benzene (Figure $6 \mathrm{~b}$ ). Protonation of benzene by proton transfer from $\mathrm{H}_{3} \mathrm{O}^{+}, \mathrm{N}_{2} \mathrm{H}^{+}$or $\mathrm{H}_{3}{ }^{+}$is well known despite its low proton affinity. ${ }^{34}$ Additionally, the protonated molecules can also be generated by a radical-mediated pathway that was shown in a recent study. ${ }^{23}$ When grounding the first disk electrode, applying $300 \mathrm{~V}$ to the second disk electrode and $30 \mathrm{~V}$ to the grid electrode, virtually all ions were suppressed in the mass spectrum of pure air (Figure $6 \mathrm{c}$ ). Using these conditions, $\mathrm{M}^{+\bullet}$ ions of benzene were still obtained (Figure 6d). Thus, the sample could be ionized without the help of any ions originating from the plasma source, providing strong evidence for ionization induced by uncharged species. However, the intensity was significantly lower (by 1 order of magnitude) compared to the measurements without potentials applied at the disk and grid electrodes. The ratio of protonated benzene to the radical cation was shifted when voltage was applied to the disk and grid electrodes. This is consistent with our hypothesis, since uncharged species generate radical cations by Penning ionization, which is an accepted mechanism in DART ${ }^{11}$. Thus, not only charged species but also uncharged species are responsible for the soft ionization of nonpolar compounds with the active capillary plasma ionization source.

a)
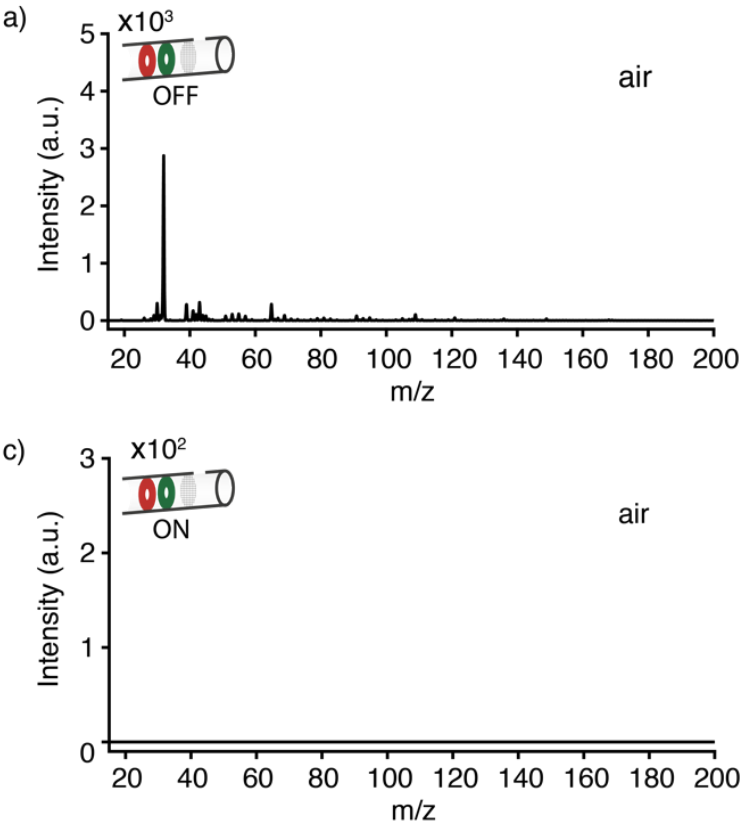

b)

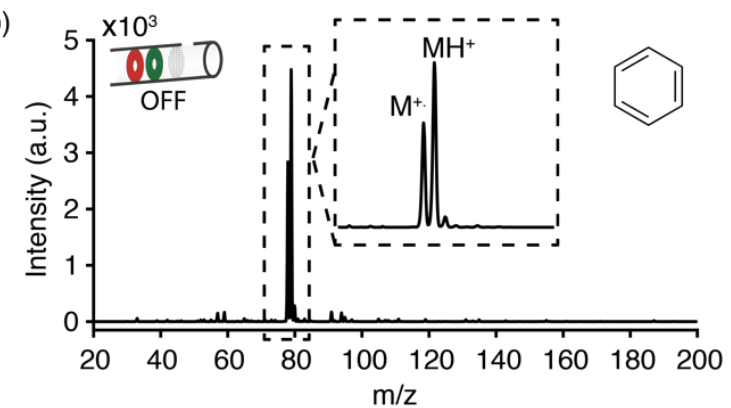

d)

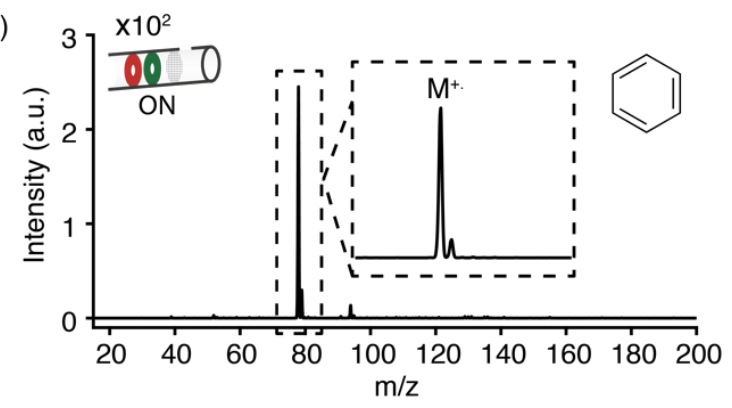

Figure 6: The mass spectrum of DBD operated in a) and c) pure air and b) and d) injection of benzene. For c) and d) voltage (1. electrode: ground, 2. electrode: $300 \mathrm{~V}$, 3. electrode: $30 \mathrm{~V}$ ) was applied on the electrodes to remove all ions before reacting with the analyte, using the home-built setup (Figure 1c). The active capillary plasma ionization source (air, $2.5 \mathrm{kV}_{\mathrm{pp}}, 47 \mathrm{kHz}$ ) was on in all four conditions. 
In this study, we revealed the factors responsible for the soft ionization of the nitrogen-operated dielectric barrier discharge ionization under controlled atmosphere. Optical emission spectroscopy as well as mass spectrometry measurements revealed a lower abundance of $\mathrm{N}_{2}{ }^{+}$in nitrogen DBD compared to helium DBD, thus implying that other reactive species such as the excited neutral nitrogen (highest optical emission), which has so far only been reported for DART, play a more important role in DBDI than expected. The softness of the ionization does not only depend on the reactive species, but also on the type of discharge and how the sample is introduced into the plasma. Soft ionization was obtained despite the presence of filamentary discharges in the nitrogen DBD if the analyte has little or no contact with these filaments. The direct contact of the analyte with the discharge filaments led to significant fragmentation. The insights about the ionization process presented in this work allow for a better understanding of crucial plasma parameters for soft ionization and an improvement of performance in different applications.

\section{ASSOCIATED CONTENT}

\section{Supporting Information}

The Supporting Information as noted in the text is available free of charge on the ACS Publications website: OES of nitrogenbased DBDI using sine and square wave; mass spectrum of butyl 2-aminobenzoate; OES of DBD using helium or nitrogen, OES of nitrogen-based DBD at different voltages, OES of DBD with nitrogen, air or carbon dioxide as discharge gas

\section{AUTHOR INFORMATION}

\section{Corresponding Author}

* E-mail: zenobi@org.chem.ethz.ch

ORCID

Renato Zenobi: 0000-0001-5211-4358

\section{Notes}

The authors declare no competing financial interest. The original data used in this publication are made available in a curated data archive at ETH Zurich (https://research-collection.ethz.ch) under the DOI 10.3929/ethz-b-000340483.

\section{ACKNOWLEDGMENTS}

The authors thank Christian Marro of the ETH mechanical workshop for manufacturing the plasma source and all relevant parts, Heinz Benz for providing and fabrication of all relevant electronic parts and Jethro Hemmann, Nora Nowak and Jonas Metternich for very helpful discussions. The authors gratefully acknowledge Dr. Juan Zhan (Novartis AG) for the donation of the LTQ Orbitrap.

\section{REFERENCES}

(1) Ding, X.; Duan, Y. Plasma-Based Ambient Mass Spectrometry Techniques: The Current Status And Future Prospective. Mass Spectrom. Rev. 2013, 34 (2), 449-473.

(2) Smoluch, M.; Mielczarek, P.; Silberring, J. Plasma-Based Ambient Ionization Mass Spectrometry in Bioanalytical Sciences. Mass Spectrom. Rev. 2015, 35 (1), 22-34.

(3) Albert, A.; Shelley, J. T.; Engelhard, C. Plasma-Based Ambient Desorption/Ionization Mass Spectrometry: State-of-the-Art in Qualitative and Quantitative Analysis. Anal. Bioanal. Chem. 2014, 406 
(25), 6111-6127.

(4) Cooks, R. G.; Ouyang, Z.; Takats, Z.; Wiseman, J. M. Detection Technologies. Ambient Mass Spectrometry. Science 2006, 311 (5767), 1566-1570.

(5) Guo, C.; Tang, F.; Chen, J.; Wang, X.; Zhang, S.; Zhang, X. Development of Dielectric-Barrier-Discharge Ionization. Anal. Bioanal. Chem. 2015, 407 (9), 2345-2364.

(6) Adamovich, I.; Baalrud, S. D.; Bogaerts, A.; Bruggeman, P. J.; Cappelli, M.; Colombo, V.; Czarnetzki, U.; Ebert, U.; Eden, J. G.; Favia, P.; et al. The 2017 Plasma Roadmap: Low Temperature Plasma Science and Technology. J. Phys. D. Appl. Phys. 2017, 50 (32), 323001.

(7) Venter, A. R.; Douglass, K. a.; Shelley, J. T.; Hasman, G.; Honarvar, E. Mechanisms of Real-Time, Proximal Sample Processing during Ambient Ionization Mass Spectrometry. Anal. Chem. 2014, 86 (1), $233-249$.

(8) Collins, C. B.; Robertson, W. W. A Flow-System and Burner for Observing Selective Excision of Spectra by Mutable Species in the Afterglow of a Helium Discharge. Spectrochim. Acta 1963, 19 (4), 747-761.

(9) Qayyum, A.; Zeb, S.; Naveed, M. A.; Ghauri, S. A.; Zakaullah, M.; Waheed, A. Diagnostics of Nitrogen Plasma by Trace Rare-Gas-Optical Emission Spectroscopy. J. Appl. Phys. 2005, 98 (10).

(10) Dzidic, I.; Carroll, D. I.; Stillwell, R. N.; Horning, E. C. Comparison of Positive Ions Formed in Nickel63 and Corona Discharge Ion Sources Using Nitrogen, Argon, Isobutane, Ammonia and Nitric Oxide as Reagents in Atmospheric Pressure Ionization Mass Spectrometry. Anal. Chem. 1976, 48 (12), 1763-1768.

(11) Cody, R. B.; Laramee, J. A.; Durst, H. D. Versatile New Ion Source for the Analysis of Materials in Open Air under Ambient Conditions. Anal. Chem. 2005, 77 (8), 2297-2302.

(12) Cody, R. B. Observation of Molecular Ions and Analysis of Nonpolar Compounds with the Direct Analysis in Real Time Ion Source. Anal. Chem. 2009, 81 (3), 1101-1107.

(13) Andrade, F. J.; Shelley, J. T.; Wetze, W. C.; Webb, M. R.; Gamez, G.; Ray, S. J.; Hieftje, G. M. Atmospheric Pressure Chemical Ionization Source. 1. Ionization of Compounds in the Gas Phase. Anal. Chem. 2008, 80 (8), 2646-2653.

(14) Shelley, J. T.; Stindt, A.; Riedel, J.; Engelhard, C. Time-Resolved Mass-Spectral Characterization of Ion Formation from a Low-Frequency, Low-Temperature Plasma Probe Ambient Ionization Source. J. Anal. At. Spectrom. 2014, 29 (2), 359-366.

(15) Na, N.; Zhao, M.; Zhang, S.; Yang, C.; Zhang, X. Development of a Dielectric Barrier Discharge Ion Source for Ambient Mass Spectrometry. J. Am. Soc. Mass Spectrom. 2007, 18 (10), 1859-1862.

(16) Bierstedt, A.; Panne, U.; Rurack, K.; Riedel, J. Characterization of Two Modes in a Dielectric Barrier Discharge Probe by Optical Emission Spectroscopy and Time-of-Flight Mass Spectrometry. J. Anal. At. Spectrom. 2015, 30 (12), 2496-2506.

(17) Kuklya, A.; Engelhard, C.; Kerpen, K.; Telgheder, U. Spectroscopic Characterization of a LowTemperature Plasma Ambient Ionization Probe Operated with Helium/Nitrogen Plasma Gas Mixtures. $J$. Anal. At. Spectrom. 2016, 31 (8), 1574-1581.

(18) Ono, R. Optical Diagnostics of Reactive Species in Atmospheric-Pressure Nonthermal Plasma. J. Phys. D. Appl. Phys. 2016, 49 (8), 83001. 
(19) Nudnova, M. M.; Zhu, L.; Zenobi, R. Active Capillary Plasma Source for Ambient Mass Spectrometry. Rapid Commun. Mass Spectrom. 2012, 26 (12), 1447-1452.

(20) Wolf, J.-C.; Schaer, M.; Siegenthaler, P.; Zenobi, R. Direct Quantification of Chemical Warfare Agents and Related Compounds at Low Ppt Levels: Comparing Active Capillary Dielectric Barrier Discharge Plasma Ionization and Secondary Electrospray Ionization Mass Spectrometry. Anal. Chem. 2015, 87 (1), 723-729. https://doi.org/10.1021/ac5035874.

(21) Mirabelli, M. F.; Wolf, J.-C.; Zenobi, R. Pesticide Analysis at Ppt Concentration Levels: Coupling NanoLiquid Chromatography with Dielectric Barrier Discharge Ionization-Mass Spectrometry. Anal. Bioanal. Chem. 2016.

(22) Mirabelli, M. F.; Wolf, J.-C.; Zenobi, R. Atmospheric Pressure Soft Ionization for Gas Chromatography with Dielectric Barrier Discharge Ionization-Mass Spectrometry (GC-DBDI-MS). Analyst 2017, 142 (11), 1909-1915.

(23) Wolf, J. C.; Gyr, L.; Mirabelli, M. F.; Schaer, M.; Siegenthaler, P.; Zenobi, R. A Radical-Mediated Pathway for the Formation of $[\mathrm{M}+\mathrm{H}]+$ in Dielectric Barrier Discharge Ionization. J. Am. Soc. Mass Spectrom. 2016, 27 (9), 1468-1475.

(24) Gyr, L.; Wolf, J. C.; Franzke, J.; Zenobi, R. Mechanistic Understanding Leads to Increased Ionization Efficiency and Selectivity in Dielectric Barrier Discharge Ionization Mass Spectrometry: A Case Study with Perfluorinated Compounds. Anal. Chem. 2018, 90 (4), 2725-2731.

(25) Massines, F.; Gherardi, N.; Naudé, N.; Ségur, P. Recent Advances in the Understanding of Homogeneous Dielectric Barrier Discharges. Eur. Phys. J. Appl. Phys. 2009, 47 (2), 22805.

(26) Wnorowski, K.; Stano, M.; Barszczewska, W.; Jówko, A.; Matejčík, Š. Electron Ionization of W(CO)6: Appearance Energies. Int. J. Mass Spectrom. 2012, 314, 42-48.

(27) Majidi, V.; Moser, M.; Lewis, C.; Hang, W.; King, F. L. Explicit Chemical Speciation by Microsecond Pulsed Glow Discharge Time-of-Flight Mass Spectrometry: Concurrent Acquisition of Structural, Molecular and Elemental Information. J. Anal. At. Spectrom. 2000, 15 (1), 19-25.

(28) Qayyum, A.; Zeb, S.; Ali, S.; Waheed, A.; Zakaullah, M. Optical Emission Spectroscopy of Abnormal Glow Region in Nitrogen Plasma. Plasma Chem. Plasma Process. 2005, 25 (5), 551-564.

(29) Lofthus, A.; Krupenie, P. H. The Spectrum of Molecular Nitrogen. J. Phys. Chem. Ref. Data 1977, 6 (1), $113-307$.

(30) Robinson, D.; Nicholls, R. W. Intensity Measurements on the O 2 + Second Negative, CO Ångström and Third Positive and NO $\gamma$ and $\beta$ Molecular Band Systems. Proc. Phys. Soc. 1958, 71, 957.

(31) Heywood, M. S.; Taylor, N.; Farnsworth, P. B. Measurement of Helium Metastable Atom Densities in a Plasma-Based Ambient Ionization Source. Anal. Chem. 2011, 83 (17), 6493-6499.

(32) Ŝnaněl, P.; Smith, D. SIFT Studies of the Reactions of H3O+, NO+ and O+2 with a Series of Volatile Carboxylic Acids and Esters. Int. J. Mass Spectrom. Ion Process. 1998, 172 (1-2), 137-147.

(33) Španěl, P.; Smith, D. Selected Ion Flow Tube Studies of the Reactions of H3O+, NO+, and O2+ with Several Aromatic and Aliphatic Monosubstituted Halocarbons. Int. J. Mass Spectrom. 1999, 189 (2-3), 213-223. 
(34) Milligan, D. B.; Wilson, P. F.; Freeman, C. G.; Meot-Ner, M.; McEwan, M. J. Dissociative Proton Transfer Reactions of $\mathrm{H} 3+, \mathrm{N} 2 \mathrm{H}+$, and $\mathrm{H} 3 \mathrm{O}+$ with Acyclic, Cyclic, and Aromatic Hydrocarbons and Nitrogen Compounds, and Astrochemical Implications †. J. Phys. Chem. A 2002, 106 (42), 9745-9755.

(35) Watanabe, K. Ionization Potentials of Some Molecules. J. Chem. Phys. 1957, 26 (3), 542-547.

(36) Worely, R. E.; A., J. F. A New Rydberg Series in N2. Phys. Rev. 1938, 54, 305.

(37) Newsome, G. A.; Ackerman, L. K.; Johnson, K. J. Humidity Effects on Fragmentation in Plasma-Based Ambient Ionization Sources. J. Am. Soc. Mass Spectrom. 2016, 27 (1), 135-143.

(38) Watanabe, K. Photoionization and Total Absorption Cross Section of Gases. I. Ionization Potentials of Several Molecules. Cross Sections of NH3and NO. J. Chem. Phys. 1954, 22 (9), 1564-1570. 
"For Table of Contents Only"

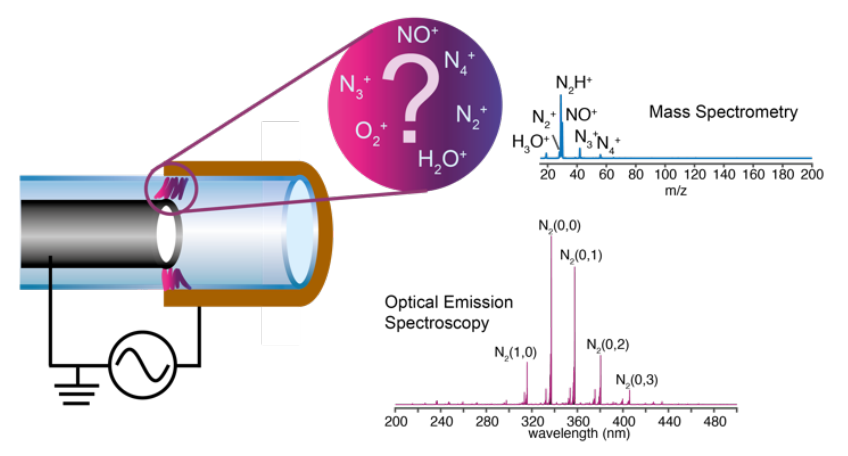

